\title{
Methods of modeling TCO residential real estate in the life cycles of buildings as a promising energy efficiency management tool
}

\author{
Kirill Kulakov ${ }^{1, *}$, Sergey Baronin ${ }^{2}$ \\ ${ }^{1}$ Moscow State University of Civil Engineering, Yaroslavskoe shosse, 26, Moscow, 129337, Russia \\ ${ }^{2}$ Penza State University of Architecture and Civil Engineering, Titova str., 28, Penza, 440027, Russia
}

\begin{abstract}
Building and developing an affordable housing market is a huge challenge for Russia's national economy. Today, the housing construction industry finds itself in a situation torn by a conflict caused by the simultaneous needs to minimize the housing construction costs in order to make housing more affordable for Russians and to increase the energy efficiency of the housing projects, which is associated with additional costs for developers. To find solutions to this contradictory situation, one needs new theoretical and practical approaches and economic tools. The global economic trend of managing goods and services on the basis of the value of goods and services over the life cycle is also manifested in the construction industry in Russia. The problem of forming a new economic thinking in the housing sector predetermines the perception of the value of housing not only as the price of purchased real estate, but as the equivalent of the total cost of ownership of real estate throughout its life cycle. This approach allows to compensate the initial rise in the cost of construction resulting from the introduction of energy-efficient technologies by savings in the operational phase of the life cycle of the property. In this regard, management of the total cost of real estate ownership based on energy modeling is of high research and practical relevance.
\end{abstract}

\section{Introduction}

The priority of building economy class housing was reiterated in the adopted the government program of the Russian Federation "Provision of affordable and comfortable housing and utility services." It involves bringing after 2016 the share of economy class housing up to $60 \%$ of the total commissioned space in residential construction. The Russian government was instructed to ensure reduction by 2018 of the cost of 1 sq.m of residential space by $20 \%$ by increasing the amount of space commissioned in economy class.

At the same time, the energy efficiency requirements in the Russian economy are becoming more stringent. For instance, the Ministry of Regional Development of the Russian Federation enacted new energy efficiency standards for construction projects requiring an increase by $15 \%$ until 2015 , by $15 \%$ after 2016 , and by another $10 \%$ after 2020. Analysis shows that the construction of all types of residential buildings, including

*Corresponding author:kkulakov@ciep.ru 
economy class projects, should be conducted with a gradual improvement of the energy efficiency standards, involving an additional increase in the cost of residential construction per square meter.

The contradictory need to reduce the cost of construction and to simultaneously increase investment in energy-efficient construction creates a problematic situation. Addressing this problem in the context of the ongoing economic crisis requires new theoretical and practical approaches and economic tools that should include the application of a methodological approach to the calculation of the cost of ownership of real estate based on the total cost over the life cycle of the real estate, as well as management of the total cost.

It should be noted that methodical approach to calculating the cost of ownership of real estate involves the conventional aspects of the global economic trend of cost management of goods and services in all areas of the national economy based on their life cycles. This approach requires the formation of a new economic thinking in the housing industry among the consumers, state and municipal authorities, and the corporate sector. The basis of the economic transformation is the perception of the notion of value of real estate not only as the local cost of acquisition, but as the cost of ownership in the form of a value equivalent of aggregated costs involved in its entire life cycle - from pre-investment feasibility study of the construction project and land acquisition to decommissioning of the property at the end of its useful life.

Individual industries of the Russian economy are already actively applying the economic tools of ownership of goods and services throughout their life cycle. For example, when buying a car, it is considered a good practice to factor in the cost of ownership, i.e. the combined costs of acquisition, maintenance, fuel, insurance over a certain period of ownership. But similar economic thinking in relation to the determination and management of the cost of ownership of residential real estate over the life cycle of their construction and operation is still in its infancy.

Studies undertaken show that foreign literature contains a sufficiently comprehensive presentation of the processes involved in determining the total cost of ownership (e.g. D.Fanning [1], J.W. Bull [2], D. Patil [3]). Also, studies have shown that European standards and research works are available in the field of regulation of the life cycle cost structure of construction, cost analysis and inclusion into contracting systems, such as DBFM, LCCA, LCC, PFI [4-11]. Despite their great importance and application prospects, they require adaptation to the modern Russian context.

In the Russian Federation, the only official methodology using this approach is the Method of calculation of the life cycle of a residential building with regard to the total costs value, enacted by the Board of the National Association of Designers on June 4, 2014 [12]. However, this method applies to a greater extent to cost estimates for use for the purposes of the Federal Law 44 FZ of 05.04.2013 "On the contract system in the procurement of goods, works and services for state and municipal needs." While the issue of managing total cost of ownership based on multivariate energy-efficient solutions over the life cycle of real estate remains unexplored.

The problem of estimating the total cost of ownership of real estate and management aspects of the total cost was addressed in the publications of several Russian researchers, among them S.A. Baronin [13,14], A.A. Benuzh [15-17], V.S. Kazeikin [18-20].

\section{Method}

After the conducted review and study of Russian and foreign research works, the authors developed an approach to calculating the cost of ownership of real estate based on total costs (Svld). It is proposed to calculate Svld in active management systems of residential real estate development. Structuring of the life cycle of residential real estate in the 
proposed method is based on three subsystems of development: land development (DL), investment and construction real estate development (DH), operational development (DM). Thus, both structure and length of the life cycle will be determined by the total values of their constituent development subsystems.

In this case, the cost of real estate ownership will be as follows:

$$
S_{v l d}=S_{[D L]}+S_{[D H]}+S_{[D M]} S \sum_{T 1}^{j}\left(\frac{z_{1 . j}}{(1+i)^{n 1 . j}}\right)+S \sum_{T 2}^{j}\left(\frac{z_{2 . j}}{(1+i)^{n 2 . j}}\right)+S \sum_{T 3}^{j}\left(\frac{z_{3 . j}}{(1+i)^{n 3 . j}}\right)(1)
$$

Where: T1, T2, T3 are periods of the life cycle of in the three subsystems of development; $i$ is the discounting rate, $z_{1 . j}, z_{2 . j}, z_{3 . j}$ are individual types of local costs of each system of development with varying degrees of aggregation.

For instance, acquisition or lease of land for land development purposes (DL) can have a different structure. This includes costs of investment marketing of land for housing construction; costs of making subdivisions and preparing them for sale at auction for state and municipal institutions or corporate costs related thereto, costs of organizing or taking part in the auctions; cost of state registration of the ownership (leasehold) title of the developer of the land, as well as other potential costs related to the sale (lease) of land. The time these activities take and the discount rate of these costs should also be taken into consideration.

Similar structuring of the costs can also be done in the phase of investment and construction development (DH). Here, traditional costs include costs of engineering surveys; design costs; costs of public expert examination; costs of onsite and offsite utilities; costs of connecting utilities; obtaining permit to commence the work; construction costs; repayment of construction loans (interest thereon); costs of obtaining commissioning permit; project decommissioning costs; planning and implementation costs of energy efficiency management as part of the estimated cost of construction (the active energyefficient share of the investment). Costs of the investment and construction phase can be structured differently. That depends on the purpose and subject of analysis.

The third subsystem of the life cycle is regarded as a stage of operational management, or operational development (DM). It can also be structured in a variety of aggregate costs. For example, operating costs of utilities; costs of major repairs; maintenance costs; costs involved in the demolition and decommissioning of the development, etc. In this case, the total costs are determined by discounting the aggregate costs of the life cycle stage T3.

In the final phase, these total costs of the three phases (development subsystems) are summed up, and correction factors can be applied to ensure comparability of different energy efficient solutions in terms of environmental friendliness and greenness of projects, their degree of energy efficiency, as well as other adjustments where they are sufficiently justified. Simplified calculations are also possible, especially in the early stages of application of the method. In that case, all correction factors assume the value of 1 , including the time factor for discounting.

Research has indicated the possibility of considering two methodical approaches to the estimation of $S_{\mathrm{vld}} \cdot S_{\mathrm{vld}}^{1}$ - this methodical approach is designed both for developers, with the purpose of bidding and participating in the tender for life cycle contracts for the construction of economy-class housing, and for calculation for public administration purposes to prepare estimates for the baseline version of the project to be used for benchmarking bids from developers.

The methodical approach is expressed by the following formula:

$$
S_{v l d}^{l}=\frac{S_{[D L]}+S_{[D H]}+S_{[D M]}}{S_{i n t}}
$$


Where $S_{\text {int }}$ is the total floor area of the residential building. $S_{\mathrm{vld}}^{2}$ - this methodical approach is designed for the buyer (owner) because the real estate in economy class for individual buyers has certain price limits at sale (RUB 30,000 per sq.m). In this case, the methodological approach uses the following formula.

$$
\mathrm{S}_{\mathrm{vld}}^{2}=\frac{\mathrm{S}_{\mathrm{ned}}+\mathrm{S}_{[\mathrm{DM}]}}{\mathrm{S}_{\mathrm{int}}}
$$

Where $S_{\text {ned }}$ is the cost of the entire property based on the prescribed selling price of economy class housing in the Russian Federation.

\section{Results}

To test the developed method, a low-rise economy-class housing project Chistye Prudy in Mokshan District, Penza Region, Russia, was chosen. Calculations for the project produced following results using the two methodological approaches to the estimation of $S_{\text {vld }}$ as shown in Figure 1.

A design life cycle of 50 years was adopted, with average life to structural repair 30 years, inflation $4 \%$, and other forecast replacement parameters. It should be noted that the value $S_{\text {vld }}^{2}$ unlike $S_{\text {vld }}^{1}$ can have a life cycle other than maximum, because property owners can have shorter ownership periods due to resale of the property. In this study, the calculation of $\mathrm{S}_{\mathrm{vld}}$ was adopted for the calculation of the full life cycle of property ownership of 50 years.

From the static consideration of the parameters of the cost of ownership of real estate we move on to the process of dynamic management based on energy modeling.

The basis of real estate cost of ownership management over its life cycle is the rational increase of the active energy efficient part of the investment designated as $S_{\text {eng }}^{\text {act }}$. It is proposed to carry out focused management of the increase of $S_{\text {eng }}^{\text {act }}$ on the basis of energy modeling, based on possible additional multivariate standard energy efficiency measures in housing, as applicable to the given property being examined.

To show the process of real estate cost of ownership, a list has been developed of 8 additional standard energy efficient designs (A-H) relevant to the context of Chistye Prudy investment project (Table 1).

Table 1. List of additional standard energy efficient designs.

\begin{tabular}{|c|c|c|c|}
\hline$\#$ & $\begin{array}{c}\text { Standard } \\
\text { design }\end{array}$ & $\begin{array}{c}\text { Specific cost per 1 } \\
\text { sq.m (RUB/sq.m) }\end{array}$ & $\begin{array}{c}\text { Average } \\
\text { payback } \\
\text { period (years) }\end{array}$ \\
\hline A & $\begin{array}{c}\text { Additional insulation of the building envelope } \\
\text { with poly } \\
\text { styrene (walls, roof) }\end{array}$ & 1020.4 & 15 \\
\hline B & Installation of apartment heat meters & 243.1 & 4 \\
\hline C & $\begin{array}{c}\text { Installation of apartment ventilation systems } \\
\text { with heat recovery }\end{array}$ & 1296.6 & 10 \\
\hline D & Installation of solar systems & 1856.7 & 10 \\
\hline E & $\begin{array}{c}\text { Installation of individual apartment heating } \\
\text { systems }\end{array}$ & 1620.7 & 35 \\
\hline F & $\begin{array}{c}\text { Using low-grade ground thermal energy in heat } \\
\text { pump systems }\end{array}$ & 5100.6 & 4 \\
\hline G & $\begin{array}{c}\text { Installation of automated heat supply units in } \\
\text { apartment blocks }\end{array}$ & 720.3 & 12 \\
\hline H & Installation of wind and solar power plants & 4074.4 & 9 \\
\hline
\end{tabular}




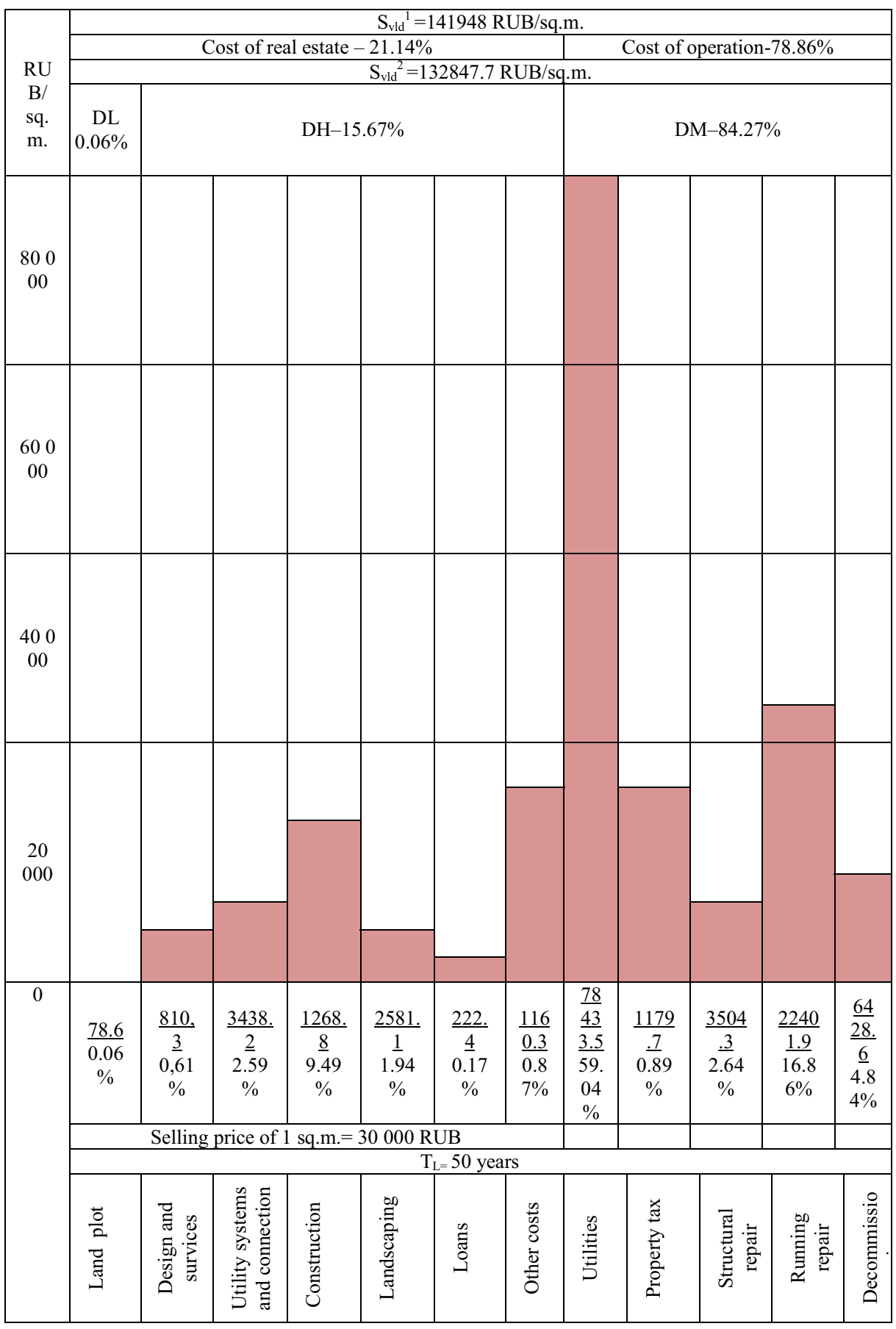

Fig. 1. Analysis of cost distribution, Chistye Prudy project.

The above energy efficiency measures are averaged and based on expert assessment and require adjustments in the context of specific design solutions for other types of investment projects. The next step was to estimate $S_{\text {vld }}$ taking into account the use of individual standard energy efficient designs, as well as their rational combinations. It is proposed, for 
real estate cost of ownership management based on indicator $S_{\text {eng }}^{\text {act }}$, to apply the following management strategies: $\mathrm{C} 1$ - management strategy based on individual energy efficiency measures with passive energy efficiency of type G; C2 - management strategy based on a combination of energy efficiency measures with passive energy efficiency of type (A+B + E); C3 - management strategy based on individual energy efficiency measures with active energy efficiency of type $\mathrm{H}$; $\mathrm{C} 4$ - management strategy based on a combination of energy efficiency measures with active energy efficiency of type $(\mathrm{C}+\mathrm{D}+\mathrm{H})$; $\mathrm{C} 5$ - management strategy based on a combination of activities with different energy efficiency performance of type $(A+D+F+G+H)$.

Application of this methodological approach has allowed to identify two types of patterns. First, a plot of the value change of the property $\left(S_{n e d}\right)$ for types $(\mathrm{C} 1-\mathrm{C} 5)$ with increasing $\mathrm{S}_{\text {eng }}^{\text {act }}$. Second, a model of the cost of real estate ownership change based on indicators $\mathrm{S}_{\mathrm{vld}}$ for types (C1-C5) with increasing $\mathrm{S}_{\text {eng }}^{\text {act }}$, as shown in Figure 2.

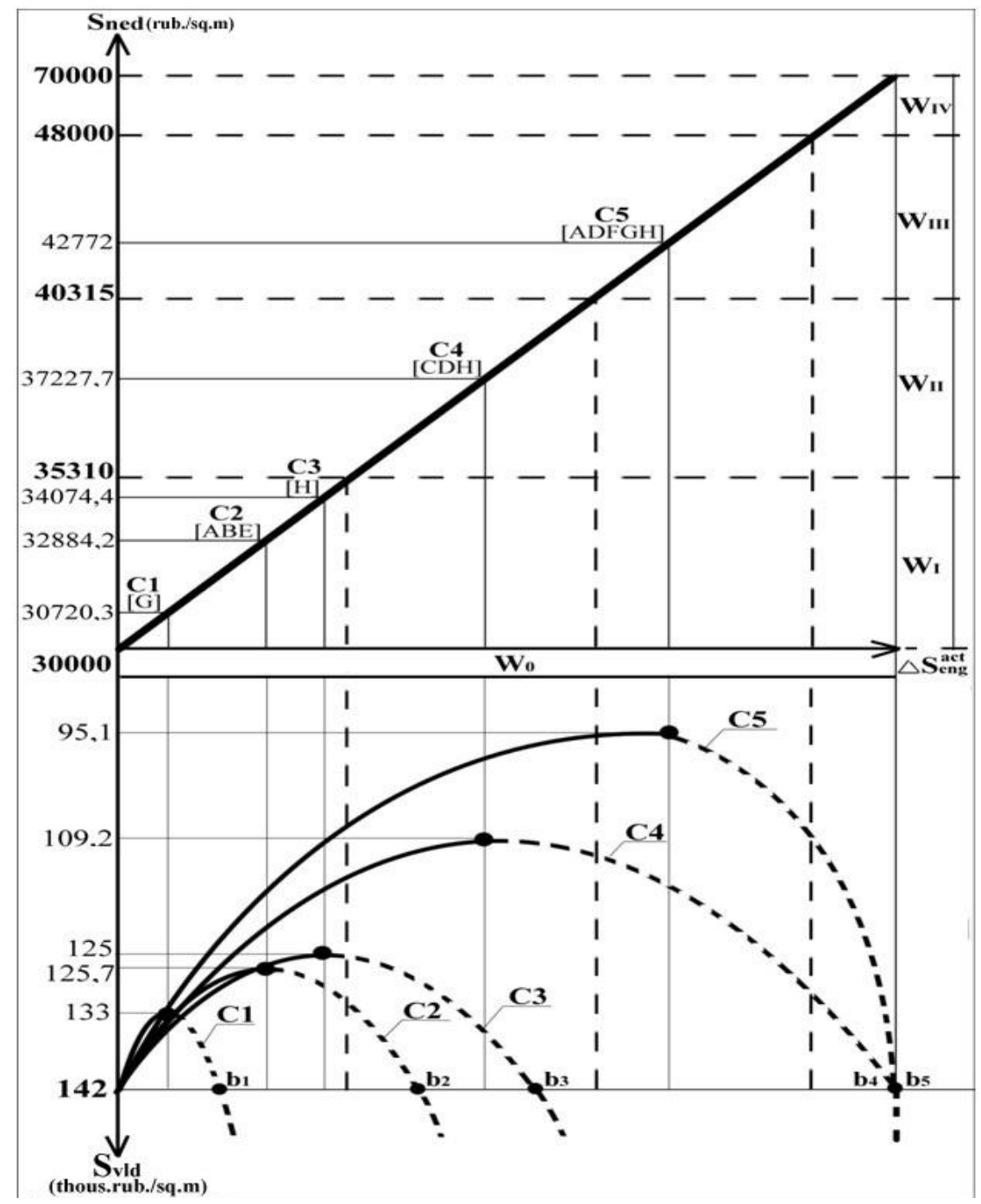

Fig. 2. Management strategies of the cost of real estate ownership based on additional standard energy efficient designs for low-rise economy class housing. 
In the upper part of Figure 2 it can be seen that the additional costs of implementing management strategies of total cost of real estate ownership proportionally increase $S_{\text {ned }}$. This, in turn, moves this type of property to a different price segment of the housing market (Wo - economy class housing $\geq$ RUB 30.000 /sq.m; WI - economy plus segment of the housing market (RUB 30.000 /sq.m $<$ WI $<$ RUB 35.310 /sq.m); WII - mid-price segment of the housing market (RUB 35.310 /sq.m < WII < RUB 40.315 /sq.m); WIII - business class segment of the housing market (RUB 40.315 /sq.m $<$ WIII $<$ RUB 48.000 /sq.m); WIV - elite segment of the housing market (RUB 48.000 /sq.m $<$ WIV)).

In the bottom part of Figure 2, the effect of the strategies adopted on the cost of real estate ownership is shown based on indicators $\mathrm{S}_{\mathrm{vld}}$, compared to the baseline value obtained in the prior calculations presented in Figure 1.

The final task involved in the verification of the proposed method was to study the effects of increasing the index $S_{\text {eng }}^{\text {act }}$ by the structure of property ownership. World experience shows that only $20 \%$ of the life cycle costs of residential property is composed of the cost of acquisition, while, on the average, $80 \%$ of the owner's total costs is incurred in the operational phase. The proposed cost of ownership calculation method has revealed the dynamics of the real estate ownership structure, subject to the application of the real estate cost of ownership management strategies $\mathrm{C} 1-\mathrm{C} 5$, as compared to the baseline scenario. The data are presented in Figure 3.

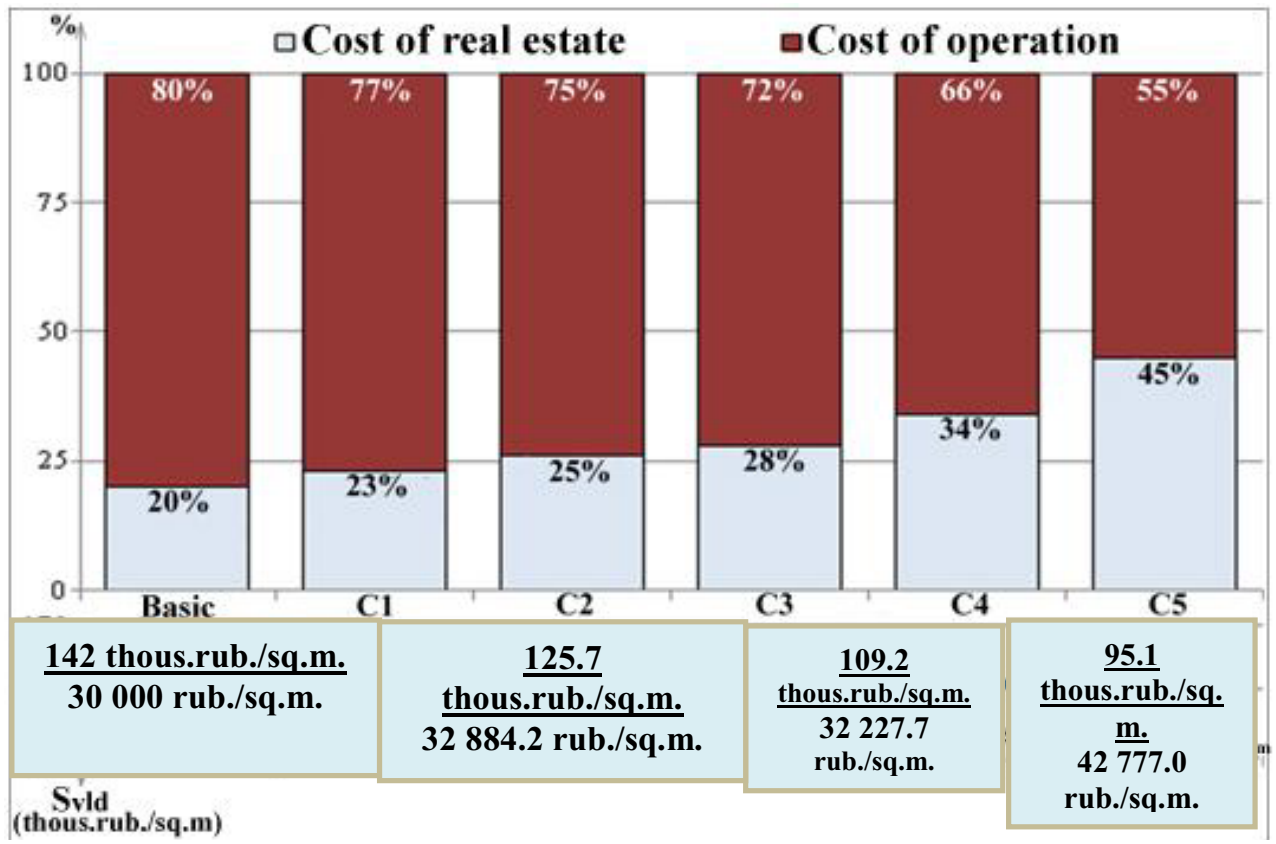

Fig. 3. Model of change in the percentage ratio of the construction costs to the operation costs within the real estate cost of ownership structure based on application of management strategies C1-C5.

An analysis of Figure 3 revealed the pattern that the increase in $\mathrm{S}_{\mathrm{eng}}^{\text {act }}$ results in the reduction of operating costs. The maximum decrease of the operating costs and the maximum increase in $\mathrm{S}_{\text {eng }}^{\text {act }}$ can be seen in strategy C5. As part of this strategy, following distribution of costs was recorded - investment and construction phase $45 \%$, operating phase $55 \%$. That said, the cost of ownership in this strategy is the lowest compared to the others - RUB 95.100 per sq.m. 


\section{Discussion}

A study of the obtained results allowed the authors to formulate proposals and practical recommendations on developing sustainable management strategies for reducing the cost of ownership of real estate on the basis of multiple energy-efficient design solutions:

1. All the proposed cost of ownership management strategies $\mathrm{C} 1-\mathrm{C} 5$ can be recommended for practical application, because they lead to a reduction in the cost of ownership;

2. The most preferred and more rational strategies are those of type $\mathrm{C} 1$ (installation of an automated heat supply unit in the apartment block), C2 (additional insulation of the building envelope with polystyrene (walls, roof) + installation of apartment heat meters + installation of individual apartment heating systems), C3 (installation of wind and solar power plants). This is due to the fact that the implementation of this type of management strategies does not lead to a significant increase in the sales price due to additional costs required to achieve a higher $S_{\text {eng }}^{\text {act }}$. They move the property to the nearest to the economy class price segment of the "economy plus" housing market;

3. For the more affluent categories of buyers in Russia, it is advisable to apply strategy C4 (installation of apartment ventilation systems with heat recovery + installation of a solar system + installation of a wind and solar power plant) and C5 (additional insulation of the building envelope with polystyrene (walls, roof) + installation of a solar system + using low-grade ground thermal energy in heat pump systems + installation of an automated heat supply unit in the apartment block + installation of a wind and solar power plant), which will ensure maximum possible energy efficiency.

However, it should be noted that the reduction of $S_{\text {vld }}$ can only be achieved if the payback period of the energy efficiency measures as part of the adopted management strategies is shorter than the life cycle of property ownership. The study has found no evidence of any energy efficiency measures with a payback period longer than the life cycle of 50 years adopted for the study. But this aspect has to be considered in calculations with different parameters and life cycle length.

\section{Conclusion}

Thus, the proposed method of estimating the total cost of ownership, as well as methodological and practical recommendations on cost of ownership management has demonstrated its development prospects. This methodical approach to real estate valuation is still in its infancy in the Russian economy. But it can become the basis of a new housing policy in the Russian Federation and the foundation of a new culture of energy-efficient home ownership. Authors believe that this should have a positive influence on the formation of a new type of thinking and home ownership culture, where the priority is the understanding of residential property from the perspective of the dynamics of maintenance costs within the life cycle of ownership and replacement. There is no doubt that further research in this area is needed in order to both implement the methodology in the public governance and to promote in Russia a new culture of home ownership.

\section{References}

1. D.Fanning, Life Cycle Costing: How to calculate life cycle costs and total ownership Cost (Create Space Independent Publishing Platform, 2014)

2. J.W.Bull, Life Cycle Costing: For the Analysis, Management and Maintenance of Civil Engineering Infrastructure(Whittles Publishing, 2013) 
3. D.Patil, Life Cycle Cost Analysis of building components (LAP LAMBERT Academic Publishing, 2011)

4. Russian Standard ISO 15686-5:2008

5. A.Boussabaine, Cost Planning of PFI and PPP Building Projects(Routledge, 2006)

6. R.J.Brawn, Introduction to life cycle costing (Prentice-Hall, 1985)

7. G.Dewulf, A.Blanken, Strategic Issues in Public-Private Partnerships (WileyBlackwell, 2012)

8. C.T.Hendrickson, Environmental Life Cycle Assessment of Goods and Services: An Input-Output Approach(Routledge, 2006)

9. J.Puil, A.Weele, International Contracting - Contract Management in Complex Construction Projects(World Scientific Publishing Company, 2013)

10. B.S.Dhillon, Life Cycle Costing for Engineers (CRC Press, 2009)

11. A.Whyte, Life-Cycle Cost Analysis of Built Assets: LCCA framework (Müller, Verlag,2011)

12. The methodology for calculating the life cycle of a residential building including total costs(Russian organization, Moscow, 2014)

13. S.A.Baronin, A.G.Yankov, S.A.Bizhanov, Life Science Journal11(8s), 249-253 (2014)

14. S.A.Baronin, A.G.Yankov, M.A.Lunyakov, Modern problems of science and education1, 45 (2015)

15. A.A.Benuzh, Construction Machinery Newsletter2(954), 58-59 (2014)

16. A.A.Benuzh, Environmental and economic model of the life cycle of a building based on the green building concept(Moscow, MGSU, 2013)

17. A.A.Benuzh, D.M.Podshivalenko, Industrial and Civil Construction10, 43-46 (2014)

18. V.S.Kazeikin, Akademstroynauka1, 264 - 269 (2012)

19. V.S.Kazeikin, M.A.Lunyakov, L.A.Manukhina,Management of economy-class housing construction based on the total cost of life cycle contracts(PGUAS, Penza,2014)

20. http://sroportal.ru/news/federal/valerij-kazejkin-v-rossii-net-specialistov-umeyushhixschitat-kontrakty-zhiznennogo-cikla/ 